\title{
ESTUDO DE CASO DO TRABALHO ESCRAVO RURAL CONTEMPORÂNEO NO BRASIL
}

CASE STUDY OF WORK CONTEMPORARY RURAL SLAVE IN BRAZIL

Beatriz Polachini ${ }^{1}$ Gabriele Ariane Pinelli²

\section{RESUMO}

Embora se trate de uma questão pouco discutida e desconhecida de grande parcela da sociedade, a escravidão contemporânea é um fato concreto e é essencial que se dê visibilidade a essa questão. Isto porque, em decorrência da vulnerabilidade e fragilidade de uma porção do corpo social, que não se mostra apto a rejeitar e se opor àquilo que lhe fora imposto, deve a sociedade, por meio da responsabilidade social, junto ao Estado, lutar em conjunto com o intuito de erradicar esse ato que viola todos os direitos e garantias fundamentais do ser humano. O trabalho tem por escopo discorrer acerca do trabalho escravo contemporâneo, dando enfoque à escravização observada no meio rural no Brasil. Ademais, tem como finalidade explicitar as razões de se tratar de conduta completamente abominável do ponto de vista legal e social. O estudo terá por base estudos e pesquisas envolvendo casos reais, análise de pesquisas atuais no que diz respeito à quantidade de pessoas sujeitas ao trabalho forçado e de empresas e pessoas físicas que cometeram o crime, bem como apreciação de artigos, legislação nacional e Convenções e Tratados Internacionais.

\footnotetext{
${ }^{1}$ Graduanda em Direito pela Faculdade de Direito de Franca.

${ }^{2}$ Graduanda em Direito pela Faculdade de Direito de Franca.
} 
Por fim, será também demonstrada a necessidade de cobrança por uma fiscalização mais incisiva e punições mais severas por parte do Estado.

Palavras-chave: Trabalho escravo contemporâneo. Meio rural. Aliciamento. Repressão ao trabalho escravo.

\section{ABSTRACT}

Although it is a matter of little discussion and ignorance of a large part of society, contemporary slavery is a concrete fact and it is essential that this issue be made visible. This is because, because of the vulnerability and fragility of a portion of the social body, which is not able to reject and oppose what was imposed on it, society must, through social responsibility, work with the State to fight with the aim of eradicating this act that violates all the fundamental rights and guarantees of the human being. The work aims to discuss contemporary slave labor, focusing on enslavement observed in rural areas in Brazil. In addition, it has the purpose of explaining the reasons for being completely abhorrent conduct from a legal and social point of view. The study will be based on studies and research involving real cases, analysis of current research regarding the number of persons subject to forced labor and of companies and individuals who have committed the crime, as well as the assessment of articles, national legislation and Conventions and International Treaties. Finally, it will also demonstrate the need for a more incisive inspection and more severe punishments by the State.

Keywords: Contemporary slave labor. Countryside. Grooming. Repression of slave labor.

\section{INTRODUÇÃO}

O trabalho escravo é a forma mais grave de exploração do homem. Não há ofensa apenas aos princípios e direitos fundamentais inerentes ao trabalho, mas também viola direitos humanos mais básicos como a dignidade, a liberdade, além da própria vida.

No Brasil, em um primeiro momento, a exploração do trabalho deu-se por meio da escravização da população indígena. Posteriormente, e com maior expressividade, com o tráfico de escravos provindos da 
África na época em que a prática era legalizada. Apesar de o sistema escravocrata ter sido abolido por meio da Lei Áurea em 13 de maio de 1888 , o trabalho escravo ainda está presente no corpo social. Todavia, nos moldes em que se encontra, o trabalho escravo já não é mais caracterizado pelo aprisionamento físico. As principais diferenças entre os regimes atual e antigo, assim, repousam no fato de que, inicialmente, o fato de um ser humano ter a propriedade de outro era totalmente legal e aceitável e, atualmente, essa prática encontra-se proibida e criminalizada.

Este trabalho tem como objetivo analisar as formas contemporâneas de trabalho escravo dando enfoque à escravização observada no meio rural no Brasil. Ademais, irá revelar as razões que levam determinada parcela da população a se sujeitar a esse tipo de situação, além de evidenciar quais providências devem ser tomadas na tentativa de erradicar a escravidão contemporânea levando-se em consideração os meios de combate já observados no país. Será abalizada, também, a forma pela qual se exterioriza o trabalho forçado no campo.

De acordo com o parâmetro exposto, figura-se como objetivo geral deste artigo científico, trazer à tona e discutir o fato de que, embora a escravidão tenha sido abolida há mais de um século, essa se retrata de maneira velada aos olhos da sociedade impedindo que grande parte da população tenha consciência e conhecimento de que se trata de uma realidade muitas vezes próxima.

Cumpre salientar que o trabalho escravo contemporâneo é vantajoso somente para quem se vale do mesmo, tendo em vista o fato de que o trabalhador não possui valor algum. Dispende-se apenas com sua manutenção, de baixo custo, além de não possuir valor de compra, o que torna extremamente simples o seu descarte. Em compensação, na realidade escravocrata do final do século XIX, o escravo era objeto de compra e venda, um verdadeiro investimento em que o custo de manutenção era elevado.

Por fim, a partir do que foi exposto acima, abordar-se-á a importância e a necessidade de eliminar tal prática condenável do ponto de vista legal e social, bem como demonstrar que, embora já existam órgãos e programas governamentais que objetivam combater a prática do trabalho escravo, é de extrema importância que haja maior fiscalização das áreas suscetíveis à ocorrência da contratação de mão-de-obra escrava, bem como estruturar e organizar adequadamente tais programas. 


\section{TRABALHO ESCRAVO CONTEMPORÂNEO NO BRASIL}

Entende-se por trabalho escravo contemporâneo aquele em que determinado indivíduo é explorado de forma ilegal, impulsionado, na maioria das vezes, pela situação de miséria em que se encontra. Tal fato o leva a sujeitar-se a prestação de serviços de qualquer natureza, em qualquer lugar e em situações degradantes.

Jairo Lins de Albuquerque Sento- Sé define trabalho escravo como:

Aquele em que o empregador sujeita o empregado a condições de trabalho degradantes, inclusive quanto ao meio ambiente em que irá realizar a sua atividade laboral, submetendo-o, em geral, a constrangimento físico e moral, que vai desde a deformação do seu consentimento ao celebrar o vínculo empregatício, passando pela proibição imposta ao obreiro de resilir o vínculo quando bem entender, tudo motivado pelo interesse de ampliar os lucros às custas da exploração do trabalhador. ${ }^{3}$

Faz-se importante destacar que a escravidão contemporânea caracteriza-se como um meio extremo de exploração econômica, sendo deixada para trás sua forma tradicional, pré-capitalista, legalizada e permitida pelo Estado. O escravo contemporâneo vê sua vontade e liberdade suprimidas pela vontade de terceiro e não recebe remuneração alguma pelos serviços realizados.

Revela-se, assim, que o trabalho escravo surge como consequência da expressiva vulnerabilidade e miséria que assola elevados contingentes de trabalhadores do país. A ausência de alternativas de trabalho digno para essas pessoas, que na maioria das vezes não possui qualificação profissional, e a precariedade do sistema de proteção social obrigam tais indivíduos a aceitarem a oferta de emprego que fere de maneira cruel a sua liberdade e a sua dignidade enquanto ser humano.

${ }^{3}$ SENTO-SÉ, Jairo Lins de Albuquerque. Trabalho escravo no Brasil na atualidade. São Paulo, LTr, 2000. p. 56. 
É possível indicar como traço marcante e definidor do trabalho escravo o vício de consentimento ao aceitar a oferta de emprego, a dificuldade criada por parte do contratante quando do encerramento da atividade, a restrição completa de liberdade do trabalhador imposta por meio de coação física ou moral e a consequente violação explícita de sua dignidade.

De acordo com Kevin Bales, "existe na sociedade uma disparidade econômica. Essa injustiça se traduz numa enorme quantidade de pessoas que, de tão pobres, se tornam vulneráveis à escravidão". ${ }^{4}$ Portanto, nota-se que o escravo possui como características marcantes a realidade de pobreza, com carência de recursos financeiros para manter a si mesmo e a sua família, ambos os sexos se sujeitam, bem como qualquer idade. Além disso, não possuem condição alguma de sobreviver em sua cidade de origem. As situações elencadas anteriormente deixam o ser humano extremamente vulnerável a aceitar propostas de uma vida melhor e mais digna.

A desigualdade econômica e social resultante da má distribuição de renda permite que o trabalho escravo ganhe grandes proporções. A escravidão contemporânea é resultado do grande número de pessoas vivendo em situação de pobreza. Essas pessoas enxergam na proposta dos aliciadores uma esperança de uma vida melhor e com mais dignidade.

Conclui-se que o trabalho forçado consiste na privação de liberdade da pessoa quando esta realiza uma atividade imposta por outra pessoa. Essa terceira pessoa coage o trabalhador, de forma física e psicológica, a realizar certo trabalho, submetendo-o a severas penas em caso do mesmo não ser realizado ou realizado de maneira diversa a solicitada. $\mathrm{O}$ trabalho escravo, ao contrário do trabalho realizado de forma justa que serve como instrumento dignificador do homem, reduz o mesmo enquanto ser humano, retirando-lhe seus direitos e garantias fundamentais.

\section{TRABALHO ESCRAVO NA ÁREA RURAL}

\section{$2.1 \quad$ CONCEITO}

\footnotetext{
${ }^{4}$ BALES, Kevin. Disposable people: new slavery in the global economy, 1999.
} 
O trabalho escravo é classificado como gênero do qual o trabalho degradante e o forçado são espécies. Ambas atentam contra a dignidade do ser humano e contra os direitos fundamentais resguardados.

$\mathrm{O}$ trabalho forçado baseia-se naquele em que há privação da liberdade quando do exercício da atividade por a pessoa se ver privada de liberdade quando do exercício de atividade imposta por uma terceira pessoa, que irá coagir o trabalhador a realizar determinado trabalho. Já o trabalho degradante é embasado no fato dos trabalhadores desempenharem a atividade sob péssimas condições de trabalho, havendo, portanto, violação dos direitos fundamentais relacionados à prestação laboral. ${ }^{5}$

A Convenção $n^{\circ} .29$ da OIT (Organização Internacional do Trabalho $)^{6}$, ratificada em 1957 pelo Brasil, traz o conceito de trabalho forçado como "todo trabalho ou serviço exigido de uma pessoa sob a ameaça de sanção e para o qual ela não tiver se oferecido espontaneamente".

Já a Convenção $n^{\circ}$. 105 da OIT $^{7}$, também ratificada pelo país, determina que:

Art. $1^{\circ}$ Todo País-membro da Organização Internacional do Trabalho que ratificar esta Convenção compromete-se a abolir toda forma de trabalho forçado ou obrigatório e dele não fazer uso: a) como medida de coerção ou de educação política ou como punição por ter ou expressar opiniões políticas ou pontos de vista ideologicamente opostos ao sistema político, social e econômico vigente; b) como método de mobilização e de utilização da mão-de-obra para fins de desenvolvimento econômico; c) como meio de disciplinar a mão-deobra; d) como punição por participação em greves; e) como medida de discriminação racial, social, nacional ou religiosa.

5 Disponível em: http://www.oitbrasil.org.br/content/perfil-dos-principais-atores-envolvi dos-no-trabalho-escravo-rural-no-brasil. Acesso em: 02.Out.2015.

6 Disponível em: < http://www.oit.org.br/sites/all/forced_labour/oit/convencoes/com v_29.pdf>. Acesso em: 20.Ago.2015.

${ }^{7}$ Disponível em: < http://www.oit.org.br/sites/all/forced_labour/oit/convencoes/conv_10 5.pdf $>$. Acesso em: 20.Ago.2015. 
Conforme as disposições das mencionadas Convenções, o trabalho forçado não será caracterizado pela simples imposição de baixos salários e ou más condições de trabalho, mas compreende também a situação de supressão da liberdade dos trabalhadores. Sendo assim, nem sempre o trabalho degradante poderá ser considerado trabalho forçado. Em contrapartida, o trabalho forçado será sempre degradante. $\mathrm{O}$ traço distintivo reside no cerceamento da liberdade.

A limitação da liberdade no Brasil está relacionada à apreensão de documentos dos trabalhadores aliciados, presença constante de guardas munidos de armas com postura ameaçadora, afastamento dos grandes centros que obsta a fuga e dívidas instituídas de maneira ilegal ${ }^{8}$.

O Brasil, utilizando a expressão "redução à condição análoga a de escravo", define o crime de trabalho escravo no artigo 149 do Código Penal ${ }^{9}$. O referido artigo prevê:

Artigo 149. Reduzir alguém a condição análoga à de escravo, quer submetendo-o a trabalhos forçados ou a jornada exaustiva, quer sujeitando-o a condições degradantes de trabalho, quer restringindo, por qualquer meio, sua locomoção em razão de dívida contraída com o empregador ou preposto. Pena reclusão, de 2 (dois) a 8 (oito) anos, e multa, além da pena correspondente à violência.

$\S 1^{\circ} \mathrm{Nas}$ mesmas penas incorre quem:

I - cerceia o uso de qualquer meio de transporte por parte do trabalhador, com o fim de retê-lo no local de trabalho;

II - mantém vigilância ostensiva no local de trabalho ou se apodera de documentos ou objetos pessoais do trabalhador, com o fim de retê-lo no local de trabalho.

$\$ 2^{\circ}$ A pena é aumentada de metade, se o crime é cometido:

I - contra criança ou adolescente;

\footnotetext{
${ }^{8}$ MARTINS, José de Souza. A reprodução do capital na frente pioneira e o renascimento da escravidão no Brasil. In: Tempo Social - Revista de Sociologia, USP, Vol. 6, nos. 1-2, 1994: 5. p. 105.

${ }^{9}$ BRASIL. Decreto-Lei no. 2.848, de 07 de dezembro de 1940. Código Penal. Disponível em:<http://www.planalto.gov.br/ccivil_03/decreto-lei/Del2848compilado.htm>. Acesso em: 20.Ago.2015.
} 
II - por meio de preconceito de raça, cor, etnia, religião ou origem.

O Código Penal Brasileiro não exige a junção de todos os fatores mencionados na letra da lei para que o crime seja caracterizado e possa ser punido. Exige apenas a presença de um dos fatores por ele elencados para que o responsável pelo crime possa ser responsabilizado ${ }^{10}$. Vale ressaltar que o artigo de lei abrangente, incluindo além das situações de falta de liberdade strictu sensu, também o trabalho degradante e em jornadas exaustivas ${ }^{11}$.

Com base em um estudo desenvolvido pela Organização Internacional do Trabalho no ano de 2011, foi traçado o perfil dos trabalhadores, aliciadores e empregadores envolvidos no cenário do trabalho escravo contemporâneo. O referido estudo apresenta informações de um grupo de 121 trabalhadores libertados que revelaram diversos aspectos de sua realidade aos pesquisadores além de haver a conceituação de trabalho escravo sob a ótica dos próprios trabalhadores, dos aliciadores, também chamados "gatos" e dos empregadores ${ }^{12}$.

De acordo com a pesquisa, a questão mais frequente, $38,8 \%$, indicada pelos trabalhadores para caracterizar o trabalho escravo é a ausência ou a baixa remuneração. Em segundo lugar, com $36,3 \%$, foi considerado como traço marcante da situação de escravidão os maus tratos e a humilhação por parte dos "gatos" e empregadores ${ }^{13}$. Sendo assim, mesmo que não esteja presente a coação física, os maus tratos e a humilhação

${ }^{10}$ COSTA, Patrícia. Estudo de caso sobre o trabalho escravo no Brasil. Brasília: Organização Internacional do Trabalho, 2010. p. 203.

${ }^{11}$ VIANA, Marco Túlio. Trabalho Escravo e "Lista Suja": um modo original de remover uma macha. In: Possibilidades Jurídicas de Combate à Escravidão Contemporânea, Brasília - Organização Internacional do Trabalho (OIT), 2007. p. 85.

12 Disponível em: <http://www.oitbrasil.org.br/content/perfil-dos-principais-atoresenvolvidos-no-trabalho-escravo-rural-no-brasil>. Acesso em: 02. Out.2015.

O estudo foi realizado no âmbito dos Projetos de Combate ao Trabalho Escravo e Combate ao Tráfico de Pessoas implementado pelo Escritório da Organização Internacional do Trabalho (OIT) no Brasil, que contou com o apoio dos governos da Noruega e dos Estados Unidos da América. A pesquisa foi realizada por um grupo de pesquisadores e pesquisadoras que colaboram com o Grupo de Estudo e Pesquisa de Trabalho Escravo Contemporâneo da Universidade Federal do Rio de Janeiro.

13 Disponível em: <http://www.oitbrasil.org.br/content/perfil-dos-principais-atoresenvolvidos-no-trabalho-escravo-rural-no-brasil>. Acesso em: 02. Out.2015. 
privam o trabalhador de sua autonomia atacando a sua dignidade. Com menos frequência foi indicada a situação equivalente a jornada exaustiva, condições de trabalho, privação de liberdade e ausência de carteira de trabalho assinada.

Para os denominados "gatos", a definição de trabalho escravo se iguala àquelas reveladas pelos trabalhadores escravizados ${ }^{14}$.

Os empregadores, em sua maioria, revelaram que o trabalho escravo consiste na privação da liberdade. A ausência de pagamento, jornada exaustiva e condições precárias de trabalho também foram fatores mencionados pelos mesmos. Vale ressaltar que houve empregadores que afirmaram não existir o trabalho escravo no Brasil e outros apenas afirmaram que esse tipo de situação não acontecia em suas propriedades rurais ${ }^{15}$.

\subsection{PROCESSO DE ALICIAMENTO E SITUAÇÃO DO TRABALHO ESCRAVO NO MEIO RURAL}

Consiste o trabalho escravo na área rural, uma das modalidades de trabalho forçado. Define a Organização Internacional do Trabalho ${ }^{16}$ como sendo trabalho forçado: "todo trabalho ou serviço exigido de uma pessoa sob ameaça de sanção e para a qual ela não tiver se oferecido espontaneamente".

O trabalho escravo, no Brasil, foi impulsionado nas décadas de 60 e 70 com a amplificação das técnicas agrícolas na Amazônia Brasileira que manifestava a necessidade de reunir diversos trabalhadores. Na contramão do que aconteceu nas décadas de 60 e 70, nas últimas décadas, nas regiões do Maranhão, Mato Grosso, Piauí e Pará, mais especificamente na zona rural, são constados os maiores casos desta prática.

\footnotetext{
14 Disponível em: <http://www.oitbrasil.org.br/content/perfil-dos-principais-atoresenvolvidos-no-trabalho-escravo-rural-no-brasil>.Acesso em: 02. Out.2015.

15 Disponível em: <http://www.oitbrasil.org.br/content/perfil-dos-principais-atoresenvolvidos-no-trabalho-escravo-rural-no-brasil>. Acesso em: 02. Out.2015.

${ }^{16}$ Organização Internacional do Trabalho. Convenção (29) sobre o trabalho forçado ou obrigatório. Disponível em: <http://www.oit.org.br/sites/all/forced_labour/oit/convenco es/conv_29.pdf>. Acesso em: 07. Ago. 2015.
} 
Com base no Relatório da Relatora Especial ${ }^{17}$, Gulnara Shahinian, e informações do Ministério do Trabalho e Emprego (MTE), restou comprovado que o Maranhão, Tocantins e Piauí são os estados brasileiros que mais fornecem trabalhadores para esse fim. Em contrapartida, os estados que mais detêm a necessidade desse tipo de trabalho são quatro: Tocantins, com 7\%, Maranhão, com 8\%, Mato Grosso, com $15 \%$ e, por fim, o estado do Pará, com $48 \%$. É fácil de notar que as atividades que mais reclamam mão de obra escrava são a pecuária, com $38 \%$, a agricultura, como a cana de açúcar, com $25 \%$, a silvicultura e desflorestamento, com $14 \%$ e as carvoarias, com 3\%. Imprescindível torna-se dizer que o fato de as atividades não reivindicarem habilidades específicas, faz com que as pessoas que não possuem algum tipo de instrução sejam atraídas para o trabalho

O sujeito que se submete à escravidão, primeiramente mascarada como uma maneira de melhorar a condição de vida sua e de sua família, é, em sua grande maioria, pessoa que se encontra em situação de extrema miséria, passando por grandes dificuldades. Essa circunstância particular em que o indivíduo se encontra, o torna vulnerável às ofertas propostas pela parte contratante que o cativam com salários atrativos, submetendo, assim, as condições degradantes e desumanas de trabalho. Com isso, normalmente, os trabalhadores são aliciados por indivíduos contratados pelo dono da propriedade rural - conhecidos como "gatos", nos estados que apresentam mais pessoas vivendo em situação de pobreza, com altos níveis de desempregados e analfabetos. Ademais, deve ser levado em consideração o fato da concentração de terras, vez que essa questão atinge de maneira incisiva os estados de origem dessas pessoas sujeitas à exploração. Portanto, os escravos rurais contemporâneos encontram-se usurpados dos meios que os permitiriam a continuar sobrevivendo na área rural, que é o cultivo da terra, subordinando-se assim, ao trabalho escravo.

\footnotetext{
${ }^{17}$ BRASIL. Ministério Público Federal. Relatório da Relatora Especial sobre formas contemporâneas de escravidão incluindo suas causas e consequências sobre sua visita ao Brasil. Disponível em: <http://pfdc.pgr.mpf.mp.br/atuacao-e-conteudos-de-apoi o/publicacoes/trabalho-escravo/relatorio-da-relatora-especial-onu-sobre-formas-contempo raneas-de-escravidao>. Acesso em: 15. Ago. 2015.
} 
Depois de aceitarem a proposta de trabalho do aliciador ${ }^{18}$, os trabalhadores dão início a sua caminhada em direção a um endividamento sem fim. Essa condição deriva do fato de que até mesmo o transporte que os levou à propriedade rural será cobrado. Não só o transporte, como também os instrumentos que serão utilizados na realização da atividade, produtos de higiene pessoal, alimentação e demais itens que os trabalhadores venham precisar, serão contabilizados. Esses utensílios são postos à disposição em um estabelecimento que se encontra no interior da fazenda em que trabalham e os valores são bem maiores do que os estabelecidos pelo mercado. Vale ressaltar que os "gatos" somam todos os gastos dos trabalhadores em uma caderneta e cada trabalhador possui a sua. Desta maneira, o trabalhador se vê impelido a continuar no local da exploração até que a sua conta seja totalmente paga. No entanto, essa dívida nunca será quitada, tendo em vista que a remuneração que recebe pelo trabalho que exerce é, ao contrário do prometido pelos "gatos", absurdamente baixa, sem falar que, pode acontecer de não receber salários por diversos meses.

O trabalho escravo compreende no ofício degradante associado à limitação da liberdade. O referido cerceamento não é explícito, devido ao fato de não mais se utilizarem meios materiais e físicos para prender o homem. Nada obstante, o motivo das propriedades rurais se localizarem longe das cidades e coação psicológica física caracterizam essa restrição de liberdade. As coações físicas e psicológicas são praticadas por pessoas armadas que inspecionam os trabalhadores durante todo tempo, e, além das ameaças de violência contra eles e até mesmo contra suas famílias, são feridos ou até mesmo mortos caso tentem fugir. Os abusos verbais e sexuais também se fazem constantes.

O tratamento degradante manifesta-se nas condições do alojamento, violência, saneamento, saúde e maus tratos. Na maioria das vezes a parte responsável por contratar os serviços não oferece um local adequado para alojar os contratados. Sendo assim, os trabalhadores acabam acomodando-se em barracas montadas ao relento, ficando sujeitos a passar frio, tomar chuva, entre outros. É importante ressaltar que os trabalhadores, ao adoecerem, são descartados de maneira rápida e sem nenhum tipo de consideração, visto que o dono da propriedade rural necessita

\footnotetext{
${ }^{18}$ SAKAMOTO, Leonardo. (Coord). Trabalho Escravo no Brasil do século XXI. 2006. OIT. Disponível em: <http://www.oit.org.br/sites/default/files/topic/forced_labour/pub/tra balho_escravo_no_brasil_do_\%20seculo_\%20xxi_315.pdf >. Acesso em: 15. Mar. 2015.
} 
exclusivamente de sua mão-de-obra, não podendo arcar com a vulnerabilidade física dos trabalhadores. Além disso, não há um sistema de saneamento básico, com tratamento de esgoto e água. Os córregos são utilizados tanto para saciar a sede das pessoas, como para os mesmos tomarem banho, lavarem suas roupas e utensílios de trabalho. Vale ressaltar que, com as chuvas, são levados para os córregos resíduos e venenos utilizados na lavoura ou na pecuária, o que prejudica ainda mais a saúde dos trabalhadores. A alimentação consiste basicamente em arroz e feijão e, às vezes, é oferecida a eles alguma "mistura". Lembrando-se de que tudo o que é consumido e utilizado pelos trabalhadores escravos rurais será contabilizado e abatido do valor que deveriam receber como pagamento pelo serviço desempenhado.

\section{REPRESSÃO AO TRABALHO ESCRAVO RURAL CONTEMPORÂNEO}

O Grupo Especial Móvel de Fiscalização é uma das formas que o Brasil possui para combater o trabalho escravo contemporâneo. O Ministério do Trabalho e do Emprego (MTE) criou, em 1995, o GMTF que é composto por auditores fiscais do MTE, delegados e agentes da polícia federal e por procuradores do Ministério Público do Trabalho.

A Secretaria de Inspeção do Trabalho do MTE leva o conhecimento das denúncias dos casos de exploração de trabalhadores ao Grupo Especial Móvel de Fiscalização, o que viabiliza que as denúncias sejam conservadas em sigilo, impedindo assim que os proprietários rurais responsáveis pela exploração tomem conhecimento e cuidem das medidas necessárias para se esquivarem das irregularidades encontradas.

O GEMF possui como finalidade constatar se as denúncias recebidas são verdadeiras. Essa verificação é feita através da fiscalização no local determinado; se proceder a informação, o Grupo toma providências como soltar os trabalhadores encontrados, sujeitos a condições análogas às de escravo e fazer constar o número de pessoas. Outra medida tomada pelo Grupo é de lavrar autos de infração contra o proprietário das fazendas em que foi constatada essa forma de exploração. A inclusão do trabalhador libertado em programas que possuem como objetivo proporcionar a acesso dessas pessoas ao mercado de trabalho é de extrema importância, 
pois é uma forma de possibilitar a geração de renda para as pessoas que dele dependem.

Entre os anos de 1995 e 2013, foram realizadas de 11 a 179 operações pelo Grupo Especial Móvel de Fiscalização, sendo resgatados 84 trabalhadores no ano de 1995 e 2.063 no ano de 2013, o que demonstra o sucesso deste Grupo no combate ao trabalho escravo.

O Cadastro de Empregadores Infratores consta como outra maneira de repreender a exploração de trabalhadores menos favorecidos. $\mathrm{O}$ Cadastro de Empregadores Infratores é um procedimento de inclusão e exclusão de nomes de pessoas físicas e jurídicas que se utilizam do trabalho escravo, estando disposto na Portaria Interministerial MTE/SDH n. ${ }^{\circ} 2$ de 12 de maio de 2011. Essa forma de combate, conhecida pela grande maioria como "lista suja", tem como propósito tornar de conhecimento geral e público o nome de empresas e pessoas físicas que se utilizam de mão de obra escrava. A inclusão do nome é feita através de uma decisão final administrativa resultante da lavratura do auto de infração em consequência de uma ação fiscal em que foram identificados trabalhadores sujeitos à exploração. Enquanto que a exclusão do nome das pessoas físicas ou jurídicas dar-se-á após o supervisionamento por 2 anos, contados a partir da data de inclusão do nome. Nesse período, irá ser observado se não houve a reincidência da prática por parte do proprietário da fazenda. Para a exclusão do nome se faz necessário o pagamento das multas derivadas dos autos de infração que foram lavrados durante a operação.

A "lista suja" é atualizada semestralmente. Nessa atualização, constam as novas inclusões e as exclusões ocorridas no semestre. A última atualização ocorreu em julho de 2014, e foram constadas 91 inclusões e 48 exclusões. O Cadastro possui 609 nomes de empregadores que utilizaram trabalhadores e os submeteram a condições análogas a de escravo. Desse número, os estados que mais apresentaram inscritos foram o Pará, Minas Gerais, Mato Grosso e, em seguida, o estado de Goiás ${ }^{19}$.

No entanto, a lista não se encontra divulgada em sua totalidade em razão do Supremo Tribunal Federal ter expedido uma medida liminar na Ação Direta de Constitucionalidade n. ${ }^{\circ}$ 5.209, proposta pela Associação Brasileira de Incorporadoras Imobiliárias (ABRAINC).

19 BRASIL. Ministério do Trabalho e Emprego. Inspeção do Trabalho: Combate ao Trabalho Escravo - Atualização Semestral de Julho/2014. Disponível em:<http://portal.mte.gov.br/trab_escravo/portaria-do-mte-cria-cadastro-de-empresas-epessoas-autuadas-por-exploracao-do-trabalho-escravo.htm>. Acesso em: 20. Mar. 2015. 
Além disso, a Portaria n. ${ }^{\circ} 1.150$ do Ministério da Integração Nacional, em concordância com a Portaria Interministerial, orienta os agentes financeiros a negarem recursos e financiamentos às empresas e pessoas físicas que estiverem constando no Cadastro de Empregadores Infratores.

A "lista suja" possui como objetivo tornar público e informar a quem possa interessar a relação que os nomes contidos nela possuem com o trabalho escravo, facultando que decidam por contratarem ou não as citadas pessoas. Ter o nome contido na referida lista não significa que receberam algum tipo de punição, já que a lista não serve para punir, mas sim para informar a sociedade das atrocidades que acontecem. A existência da lista indica que houve uma fiscalização, seguida de uma lavratura de auto de infração e de uma instauração de processo administrativo.

O Ministério Público Do Trabalho também atua com o fím de combater a prática da escravidão contemporânea. O MPT atua de maneira judicial, por meio da ação anulatória, a ação civil pública, a ação preventiva, e extrajudicialmente, por meio do inquérito civil público e o termo de ajuste de conduta (TAC), de forma a proteger direitos coletivos e individuais, além de atuar de forma a erradicar o trabalho forçado.

É de suma importância falar sobre o "Plano Nacional para a Erradicação do Trabalho Escravo", lançado em 11 de março de 2003 pelo então presidente Luiz Inácio Lula da Silva. Subsequentemente, foi lançado o "2. " Plano para a Erradicação do Trabalho Escravo" em 17 de abril de 2008, para complementar o primeiro.

A apresentação do primeiro plano revela que:

Consciente de que a eliminação do trabalho escravo constitui condição básica para o Estado Democrático de Direito, o novo Governo elege como uma das principais prioridades a erradicação de todas as formas contemporâneas de escravidão. E o enfrentamento desse desafio exige vontade política, articulação, planejamento de ações e definição de metas objetivas. ${ }^{20}$

${ }^{20}$ BRASIL. Ministério do Trabalho e Emprego. $1^{\circ}$ Plano Nacional para Erradicação do Trabalho Escravo. 2003. Disponível em: <http://portal.mte.gov 
Já na apresentação do segundo plano, afirma que:

Este 2. ${ }^{\circ}$ Plano Nacional para a Erradicação do Trabalho Escravo foi produzido pela Conatrae Comissão Nacional para a Erradicação do Trabalho Escravo e representa uma ampla atualização do primeiro plano, Aprovada em 17 de abril de 2008, esta nova versão incorpora cinco anos de experiência e introduz modificações que decorrem de uma reflexão permanente sobre as distintas frentes de luta contra essa forma brutal de violação dos Direitos Humanos. ${ }^{21}$

As finalidades traçadas em ambos os planos, indicam como responsáveis órgãos dos poderes Legislativo, Executivo e Judiciário. As entidades devem atuar de forma a combater de forma a eliminar essa chaga, que é o trabalho escravo, do corpo social, pois ela continua a afrontar e violar direitos básicos e fundamentais dos seres humanos. As entidades governamentais envolvidas no combate ao trabalho escravo contemporâneo afirmam que os Planos de Erradicação se mostram limitados quanto à sua eficácia por não existirem pessoas suficientes para colocarem em prática as metas estabelecidas nos planos. No entanto, não há falta de pessoas somente para colocarem os planos em prática, há falta também de juízes do trabalho, procuradores da República, entre outros profissionais aptos a atuarem de forma erradicar essa mazela. A liberação de verba por parte do Estado também se mostra insuficiente para saldar os gastos necessários com profissionais e atuações destes. Ter leis e Planos para atuarem na repressão do trabalho escravo se faz necessário, no entanto, de nada adianta a existência deles se o Estado não oferecer subsídios para os órgãos existentes colocarem em prática os objetivos das leis e Planos.

\section{$4 \quad$ ANÁLISE DE CASO}

.br/data/files/FF8080812B21345B012B2ABF15B50089/7337.pdf>. Acesso em: 25. Ago. 2015.

${ }^{21}$ BRASIL. Ministério do Trabalho e Emprego. $2^{\circ}$ Plano Nacional para Erradicação do Trabalho Escravo. 2008.Disponível em: <http://portal.mte.gov.br/data/files/8A7C816 A39E4F614013AD5A314335F16/novoplanonacional.pdf>. Acesso em: 25. Ago. 2015. 
A seguir expõe-se o estudo de caso cuja gestão e execução de projeto foram realizadas pelo Instituto Brasileiro de Inovações PróSociedade Saudável da Região Centro-Oeste e cujo relatório final foi elaborado por Estela Márcia Rondina Scandola e Roberluce Oliveira Bra$\mathrm{ga}^{22}$.

Após a libertação dos trabalhadores submetidos à condição análoga a de escravo, por meio de denúncia realizada pelo "disque denúncia", houve a necessidade de inserção dessas pessoas, novamente, no meio social comum, possibilitando o acesso das mesmas a todas as políticas sociais disponibilizadas pelo Governo, além de possibilitar a regularização dos haveres trabalhistas e o retorno às cidades de origem. O objetivo da operação é, ao menos, suavizar os efeitos da escravidão na vida de cada uma das pessoas libertadas, bem como evitar que haja reincidência na prática supracitada.

As fazendas fiscalizadas foram Bodoquena e Pitangueiras, ambas situadas no município de Bonito - MS e Rosemary, situada no município de Maracajú - MS. Para tanto, foram acionados os seguintes Órgãos: a Procuradoria Regional do Trabalho da $24^{a}$ Região do Ministério Público do Trabalho, a Superintendência Regional do Trabalho, a Polícia Federal e a Comissão Permanente de Investigação e Fiscalização das Condições de Trabalho no Mato Grosso do Sul, a qual é representada por servidores públicos e representantes de organizações da sociedade civil.

A realidade encontrada nos locais apresentados acima mescla trabalho degradante aliado ao cerceamento da liberdade, que não pode ser observada em um primeiro momento por não haver utilização de meios físicos que literalmente prendam os trabalhadores. Os empregadores utilizam, assim, meios de coação psicológica para obrigarem os trabalhadores a permanecer submetidos às condições impostas. Vale-se, também, da situação de vulnerabilidade social e econômica a qual estão inseridos, o que permite que os trabalhadores não relutem contra o sistema de trabalho, sem dignidade ou direitos assegurados.

\footnotetext{
${ }^{22}$ RONDINA SCANDOLA, Estela Márcia; OLIVEIRA BRAGA, Roberluce. A realidade dos homens retirados do trabalho escravo um ano depois - O caso das fazendas Bodoquena, Pitangueiras e Rosemary no estado do Mato Grosso do Sul. Relatório Final. Disponível em <http://traficodepessoas.org/site/wp-content/uploads/2013/06/Relatorio-Arealidade-dos-homens-retirados-do-trabalho-escravo.pdf?1cd2be>. Acesso em: 01. Out. 2015.
} 
No dia 25 de março de 2010 houve a primeira fiscalização, iniciando-se pela Fazenda Pitangueiras. No dia seguinte, dia 26 de março, a equipe seguiu para a Fazenda Bodoquena. Em ambas foram encontradas irregularidades que feriam a dignidade de cada trabalhador além de colocar em risco sua saúde. Aa irregularidades observadas contrariam as Normas Regulamentadoras NR 31, no que diz respeito à Segurança e Saúde no Trabalho na Agricultura, Pecuária, Silvicultura, Exploração Florestal e Aquicultura; NR 24, Condições Sanitárias e de Conforto nos Locais de Trabalho; NR 21, Trabalhos a céu aberto; NR 12, Segurança no Trabalho em Máquinas e Equipamentos; NR 8, Edificações; NR 6, Equipamento de Proteção Individual (EPI).

Não haveria sentido passar por todo o processo de libertação se não fosse exigido do responsável a regularização dos haveres trabalhistas. Ademais, todos os trabalhadores foram devidamente indenizados, recebendo, ainda, um valor equivalente à passagem para o retorno ao município de origem de cada pessoa.

Já na Fazenda Rosemary, cuja operação se iniciou no dia 06 de dezembro de 2011, também foi constatada situação de trabalho em condições degradantes. Os trabalhadores executavam os serviços expostos a riscos de saúde por não utilizarem os equipamentos de segurança exigidos para desempenhar certas funções, bem como utilizavam um córrego com o fim de tomar banho, fazer suas necessidades, lavar roupas além de utilizar a água para o consumo próprio. Nesse caso, houve também a regularização da situação trabalhista das pessoas atingidas, ocorrendo as devidas modificações.

É importante destacar que, por meio das operações de libertação e posterior trabalho desenvolvido junto aos trabalhadores, foi possível identificar o perfil de cada trabalhador, que incluiu a idade e origem, raça e etnia, vida conjugal, filhos e convívio familiar, escolaridade, formação profissional, em quais programas sociais do governo estavam inseridos, entre outros.

De uma maneira geral, concluiu-se que os trabalhadores são pessoas carentes de recursos financeiros que se viram diante de uma oportunidade de melhorar as condições de vida por meio da oferta de emprego pelos aliciadores. Além disso, a maioria deles são homens que possuem o ensino fundamental incompleto ou são semialfabetizados e que desfrutavam de condições precárias de vida. 
A conclusão final da análise foi no sentido de que poucos trabalhadores conseguiram, de maneira efetiva, retornar ao mercado de trabalho para prover o seu sustento e de sua família. O sentimento com relação à situação na qual viviam é contraditório, tendo em vista que, enquanto alguns deles demonstram indignação e não pensam em voltar a desempenhar aquele dito papel, outros afirmaram que o trabalho na fazenda era a única oportunidade de emprego que surgiu para possibilitar a subsistência, não reconhecendo que se tratava de algo proibido, que feria de maneira acentuada todos os seus direitos e garantias fundamentais.

Ademais, concluiu-se que todos os Órgãos e Organizações envolvidos nas operações de libertação e pós-libertação atuaram da maneira devida, de acordo com o que era exigido. Contudo, mesmo cumprindo com o seu papel, as ações não foram suficientes para proporcionar uma melhora nas condições de vida de cada trabalhador, uma vez que muitas vezes aquelas careciam de estrutura, suporte e pessoal para desempenhar de maneira plena a função. Desta maneira, foram elencados diversos aspectos que deveriam ser mudados para que os efeitos fossem alcançados. Entre esses apontamentos estão: tornar possíveis ações para a reversão do quadro de vulnerabilidade no qual se encontram os trabalhadores, qualificar de grupos municipais para a promoção de direitos, prevenir aliciamento e atendimento emergencial, apoiar o fortalecimento de organizações da sociedade civil, manter um sistema de acompanhamento dos trabalhadores e da ação de políticas sociais, entre outros.

A mudança somente será possível se houver a alteração da estrutura de desigualdade social na qual a sociedade está inserida, a fim de garantir que todas as pessoas tenham acesso de maneira igualitária a todos os meios de trabalho dignos e que permitam que cada pessoa tenha uma vida minimamente confortável, principalmente no que diz respeito ao sustento da mesma e de sua família. O trabalhador não deve continuar inserido na situação de "não direito", baseado no conformismo, mas ser colocado em patamar de igualdade com todos os cidadãos brasileiros.

\section{CONSIDERAÇÕES FINAIS}

No desenrolar do trabalho, notou-se que a questão do trabalho escravo é um fato concreto no país e demanda grande atenção por parte do corpo social, bem como dos órgãos públicos. Todas as modalidades de 
escravidão ferem os direitos fundamentais do ser humano, os quais estão previstos e são protegidos por acordos e convenções internacionais, além da Constituição Federal e legislações infraconstitucionais nacionais.

Restou demonstrado que a tormenta não é voltada apenas para o trabalho escravo em si, mas também aos efeitos e reflexos deste na economia do país e para os proprietários das propriedades rurais onde o trabalho escravo em sua feição contemporânea é encontrado, ao modo de se obstar tais condutas, bem como na realidade que os trabalhadores libertados encaram posteriormente a saída das terras nas quais eram escravizados.

Ademais, verificou-se que o Brasil é signatário de duas importantes Convenções da Organização Internacional do Trabalho e possui uma legislação farta de disposições, medidas e sanções a serem aplicadas contra aqueles que transgredirem os direitos fundamentais do ser humano ao submetê-los ao regime de escravidão.

Apesar de existirem preceitos, planos e diretrizes a serem perseguidos pelo Governo, notou-se que ainda não há garantia de eliminação do trabalho escravo por meio da aplicação dos mesmos, vez que ainda há elevados números de pessoas físicas e jurídicas ligadas a essa prática.

Posteriormente à análise dos métodos elencados para a erradicação do trabalho escravo contemporâneo, pode-se destacar que, para que haja efetivação das medidas, é necessário que se libere maior verba com o objetivo de melhorar e adequar a infraestrutura, a fiscalização e oferecer quantidade de material de consumo suficiente para as operações. Além disso, as entidades governamentais envolvidas apontam que há carência acentuada de recursos humanos, de pessoas qualificadas para fazerem cumprir as metas e medidas no que respeita à erradicação do trabalho escravo. Essa infeliz realidade prejudica o melhoramento da estrutura dos Grupos Móveis de Fiscalização, por exemplo. Há também escassez de procuradores da República e do Trabalho, Juízes do Trabalho Federais, auditores fiscais do trabalho, polícia federal e polícia rodoviária federal, técnicos do INCRA e IBAMA, além de funcionários públicos que devem estar presentes nos processos de libertação e análise posterior dos casos a fim de fazer valer certos direitos dos trabalhadores libertados.

É essencial que haja maior comunicação entre os órgãos do poder público com todas as entidades envolvidas com a finalidade de se observar maior eficiência no combate e repressão do trabalho escravo e, além disso, que se adentrem novos atores no processo de conscientização 
social, principalmente os formadores de opinião pública. A sensibilização do corpo social também é um essencial na luta pela libertação dos trabalhadores escravizados, bem como na prevenção do aliciamento.

Existem leis e medidas aptas a produzir os efeitos esperados quanto à erradicação das formas contemporâneas de trabalho escravo. Contudo, ainda não são eficazes do ponto de vista prático, ou seja, apesar de existir o aparato necessário, os números relativos às pessoas responsáveis por aliciar e escravizar pessoas não tem sofrido diminuição considerável no decorrer do tempo. Tal fato pode ser comprovado por meio de observação dos dados oferecidos pelo Ministério do Trabalho e do Emprego, conforme foi citado ao longo do trabalho.

Conclui-se que a escravidão contemporânea é uma realidade e caracteriza-se como crime em que seus autores não podem e não devem deixar de sofrer punição por parte do Estado. Ademais, essa realidade não pode permanecer oculta aos olhos da sociedade, uma vez que envolve a supressão de direitos e garantias mais básicos do cidadão brasileiro. A escravatura foi abolida há mais de um século e é substancial que sua feição contemporânea seja extirpada.

\section{REFERÊNCIAS BIBLIOGRÁFICAS}

BALES, Kevin. Disposable people: new slavery in the global economy, 1999.

BRASIL. Decreto-Lei $n^{\circ}$. 2.848, de 07 de dezembro de 1940. Código Penal. Disponível em: <http://www.planalto.gov.br/ccivil_03/ decreto-lei/Del2848compilado.htm>. Acesso em: 20.Ago.2015. Ministério do Trabalho e Emprego. 1. Plano Nacional para Erradicação do Trabalho Escravo. 2003. Disponível em: <http://portal.mte.gov.br/data/files/FF8080812B21345B012B2AB F15B50089/7337.pdf >. Acesso em: 25. Ago. 2015.

Ministério do Trabalho e Emprego. 2. Plano Nacional para Erradicação do Trabalho Escravo. 2008. Disponível em: <http://portal.mte.gov.br/data/files/8A7C816A39E4F614013AD5A 314335F16/novoplan onacional.pdf >. Acesso em: 25. Ago. 2015.

Ministério do Trabalho e Emprego. Inspeção do Trabalho: Combate ao Trabalho Escravo - Atualização Semestral de Julho/2014. Disponível em: <http://portal.mte. gov.br/trab_escrav 
o/portaria-do-mte-cria-cadastro-de-empresas-e-pessoas-autuadaspor-exlor acao-do-trabalho-escravo.htm>. Acesso em: 20. Set. 2015.

. Ministério do Trabalho e Emprego. Quadro Geral das Operações de Fiscalização para a Erradicação do Trabalho Escravo SIT/SRTE. Disponível em: <http://portal .mte.gov.br/da ta/files/8A7C816A45B26698014625BF23BA0208/Quadro\%20res umo\%20op e ra\%C3\%A7\%C3\%B5es\%20T.E.\%201995\%20\%202013.\%20Inernet.pdf>. Acesso em: 20. Mar. 2015.

. Ministério Público Federal. Relatório da Relatora Especial sobre formas contemporâneas de escravidão incluindo suas causas e consequências sobre sua visita ao Brasil. Disponível em: <http://pfdc.pgr.mpf.mp.br/atuacao-e-conteudos-de-apoio/publ icacoes/trabalho-escravo/relatorio-da-relatora-especial-onu-sobreformas-contemporaneas-de-escravi dao>. Acesso em: 15. Ago. 2015.

COSTA, Patrícia. Estudo de caso sobre o trabalho escravo no Brasil. Brasília: Organização Internacional do Trabalho, 2010.

GOMES, Luiz Flávio. Crimes contra a humanidade: conceito e Imprescritibilidade (Parte II). Disponível em: <http://lfg.jus brasil.com.br/noticias/1633577/crimes-contra-a-humanidadeconceito-e-imprescritibilidade-parte-ii >. Acesso em: 01.Ago.2015.

HASHIZUME, Maurício; PYL, Bianca. Roupas da Zara são fabricadas com mão de obra escrava. 2011. Disponível em: $<$ http://reporterbrasil.org.br/2011/08/roupas-da-zara-sao-fabrica das-com-mao-de-obra-escrava/>. Acesso em: 10.Ago.2015.

LIMA, Luciana Golçalves de. Trabalho Escravo Rural Contemporâneo na Agenda do Estado Brasileiro: políticas de enfrentamento. 2013. Disponível em <http://www.joinpp.ufma.br/jornadas/joinpp

2013/JornadaEixo2013/anais-eixo3-estadolutassociaisepolit icaspublicas/trabalhoescravoruralcontemporaneonaagendadoe stadobrasileiro-politicasdeenfrentamento.pdf>. Acesso em: 15.Set.2015.

MARTINS, José de Souza. A reprodução do capital na frente pioneira e o renascimento da escravidão no Brasil. In: Tempo Social Revista de Sociologia, USP, Vol. 6, nos. 1-2, 1994: 5.

NASCIMENTO, Arthur Ramos do. COELHO, Saulo de Oliveira Pinto. Trabalho Escravo Rural no Brasil Contemporâneo: 
considerações iniciais sobre o estudo das normas, instrumentos jurídicos, atuação estatal e realidade social brasileira. 2011. Disponível em <https://www.cienciassociais.ufg.br/up/106/o/ 0102_2011x.pdf>. Acesso em: 08.Set.2015.

Organização Internacional do Trabalho. Convenção (29) sobre o trabalho forçado ou obrigatório. Disponível em: <http://www.oit .org.br/sites/all/forced_labour/oit/convencoes/conv_29.pdf >.

Acesso em: 07.Ago.2015.

- O perfil dos principais atores envolvidos no trabalho escravo rural no Brasil/. Brasília: OIT, primeira edição, 2011. Disponível em $<$ http://www.justica .sp.gov.br/StaticFiles/SJDC/ArquivosComuns/ProgramasProj etos/NETP/Relat\%C3\%B3rio\%20OIT.\%20Trabalho\%20Escr avo\%20Rural\%20Brasil.\%202011.pdf>. Acesso em 20.Ago.2015.

SCANDOLA, Estela Márcia Rondina; OLIVEIRA BRAGA, Roberluce. A realidade dos homens retirados do trabalho escravo um ano depois - $\mathrm{O}$ caso das fazendas Bodoquena, Pitangueiras e Rosemary no estado do Mato Grosso do Sul. Relatório Final. Disponível em $<$ http://traficodepess oas.org/site/wp-content/uploads/2013/06/Relatorio-A-reali dade-dos-homens-retirados-do-trabalho-escravo.pdf?1cd2be >. Acesso em: 01.Out. 2015.

SAKAMOTO, Leonardo. (Coord). Trabalho Escravo no Brasil do século XXI. 2006. OIT. Disponível em: <http://www.oit.org.br/sites/def ault/files/topic/forced_labour/pub/trabalho_escravo_no_brasil_do_ \%20seculo_\%20xxi_315.pdf>. Acesso em: 15. Set. 2015.

SENTO-SÉ, Jairo Lins de Albuquerque. Trabalho escravo no Brasil na atualidade. São Paulo, LTr, 2000.

UNESCO. Declaração Universal dos Direitos Humanos. 1948. Disponível em: <http://unesdoc. unesco.org/images/0013 /001394/139423por.pdf>. Acesso em: 10. Set. 2015.

VIANA, Marco Túlio. Trabalho Escravo e "Lista Suja": um modo original de remover uma macha. In: Possibilidades Jurídicas de Combate à Escravidão Contemporânea, Brasília - Organização Internacional do Trabalho (OIT), 2007. 
VIEIRA, Jorge Antonio Ramos. Trabalho escravo: quem é o escravo, quem escraviza e o que escraviza. Palestra proferida no XVIII CONGRESSO BRASILEIRO DE MAGISTRADOS, Salvador/BA, 2003. 
